\title{
Parenting Style and Child's Obesity: A Systematic Review
}

\author{
Wiwin Lastyana ${ }^{1}$, Asih Setiarini ${ }^{1, *}$ \\ ${ }^{1}$ Universitas Indonesia, Depok, Indonesia \\ * Corresponding Author. Email: asih.setiarini@gmail.com
}

\begin{abstract}
This paper presents an overview to provide readers with an update on the literature about the relation between parental influences (general parenting and food parenting practices) and children's weight-related outcomes. A systematic research review following PRISMA guidelines was conducted to identify, discuss and integrate recent research investigating the relationship between parenting styles, child's obesity. It first summarizes the evidence regarding the role of food parenting practices in shaping and maintaining children's nutritional and weight status. It then describes empirical evidence on the relation between general parenting and children's weight status. Six electronic databases were searched using standardized language to identify quantitative studies describing associations of general parenting styles with children's obesity aged 3-5 years. Eligible peer-reviewed journal articles published between 2010 and 2019 were included. Eleven studies met inclusion criteria. Few studies focused on general feeding. Most studies focused on controlling food parenting practices and general parenting style. Parental restriction of food was positively associated with child obesity, while pressure to eat and monitoring yielded inconsistent results. Parenting styles were consistently associated with obesity among young children. Research is needed to identify positive parenting behaviors around child's weight that may be used as targets for health promotion.
\end{abstract}

Keywords: child's obesity, food parenting, parenting style

\section{INTRODUCTION}

According to WHO Overweight and obesity are defined as abnormal fat accumulation which will cause health risks. Body Mass Index (BMI) is used to measure obesity in the population, a person's weight (in kilograms) divided by height (in meters) that squared. Someone with a BMI of $30 \mathrm{~kg} / \mathrm{m}^{2}$ or more offered are into group obesities. A person with a BMI over or equal to $25 \mathrm{~kg} / \mathrm{m}^{2}$ are categorized in excess weight [1].

Being overweight and obese are the main factors causing chronic diseases including diabetes, cardiovascular, and cancer. Previously, this problem was high only in urban areas or high-income countries, but in middle and developing countries it also began to occur [2].

Based on Riskesdas data in 2018 the proportion of obesity in adults has increased from $14.3 \%$ to $21.8 \%$ in 2018 . The proportion of center obesity in adults $>15$ years has also increased from $26.6 \%$ in 2013 to $31 \%$ in years $n 2018$ [3]. Several causes of obesity in children are known, namely genetic, environmental, intake and duration and quality of sleep. Environmental factors such as parents act as models and regulators for their children. Therefore, the environment and specific characteristics of the family cannot be a risk factor for obesity and overweight in children [4]. Children learn what, when and how much brands should eat from paying attention to the eating habits of their families. Some previous studies have shown that one or both parents are obese or overweight apparently contribute significantly as one of the factors of their children obesities and overweight [5].

This systematic review was conducted to identify, discuss, and integrate the latest research that explores parenting styles that increase or reduce the risk of obesity in children aged 3-5 years.

\section{METHOD}

This systematic review was made from August 2019 to September 2019 using the PRISMA reporting guidelines. Based on this guide, here are some steps in this study: 1) finding criteria; 2) find information sources; 3) study selection; 4) the process of collecting data; and 5) data selection. 
Literature Search

Database: Springer, Elsevier (Scopus), Science Direct

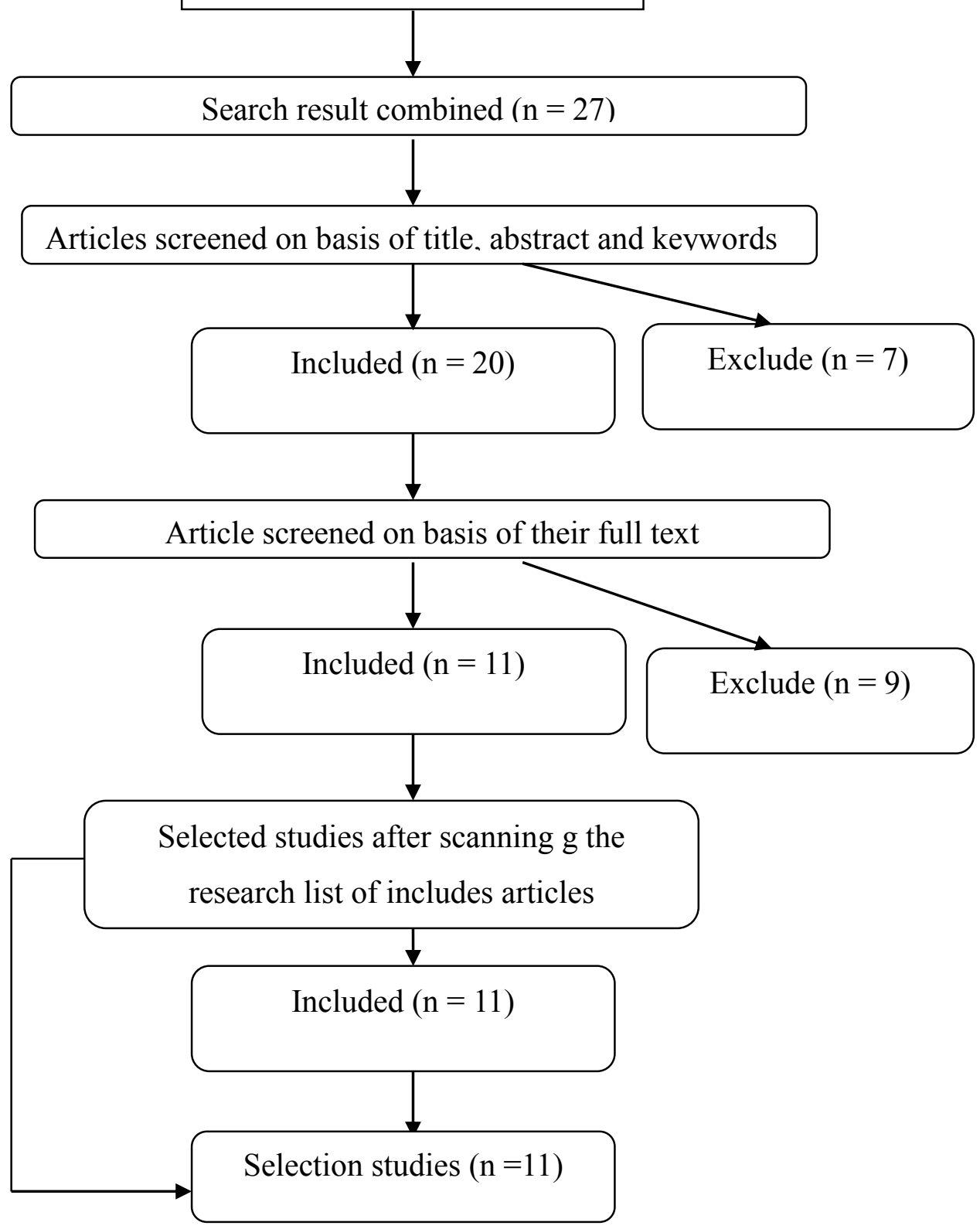

Figure 1. Diagram PRISMA 


\section{Eligibility criteria}

Inclusion criteria specified for review guidelines:

IC1: Original article in English and

IC2: Research aims to determine the relationship of parenting style with the incidence of obesity in children.

Only articles in English were selected, because English is the language commonly used by researchers in the scientific community.

\section{Resources}

Researchers searched online databases with extensive academic research repositories including Elsevier (SCOPUS), Science Direct and Springer. Researchers eliminate articles that cannot be fully accessed by the author. In addition, the authors scanned the list of references included in the articles to find related matters.

\section{Data Collection Process}

Data collection uses manual methods by breaking down the data into, type of article, journal name or title, participants, country, research methods and results.

\section{RESULTS AND DISCUSSION}

\section{Study Selection}

Search results in the chosen database provide a total of 27 studies written in English from 2010 to 2019, matching the keywords that need to be analyzed. Next, the articles are filtered by title, abstract, and keywords; the remaining 20 articles are then reviewed based on the full text. A total of 9 articles were not included because they do not relevant the topics to be discussed. Finally, a total of 11 articles were selected in the review without additional articles resulting from scanning the reference list.

\section{Study Characteristics}

This section explains demographic data items from 11 selected articles. The results of this study indicate that 11 studies identified parenting styles with obesity or overweight. Detailed demographics of relevant papers are explained in Tables 1 and 2

Table 1. Distribution of used articles

\begin{tabular}{ccc}
\hline Category & Country & $\begin{array}{c}\text { Number of } \\
\text { Publication }\end{array}$ \\
\hline Developed country & Canada & 2 \\
& Finland & 1 \\
& USA & 3 \\
& Netherlands & 1 \\
& Minnesota & 1 \\
& South Australia & 1 \\
& Austria & 1 \\
Developing country & China & 1 \\
\hline
\end{tabular}

In the table it can be explained that the journal articles used after selection by the PRIMA method are 11 articles in which most articles are from developed countries $(n=10)$, whereas there is only one article from developing countries. This is because articles that are relevant to the topic of researchers are more found in developed countries compared to developing countries.

Table 2. Distribution of Research Methods Used

\begin{tabular}{ccc}
\hline Method & Type of Study & $\begin{array}{c}\text { Number of } \\
\text { Publication }\end{array}$ \\
\hline Quantitative & $\begin{array}{c}\text { Questioner } \\
\text { survey }\end{array}$ & 7
\end{tabular}

Literature of Review

4

In the table, it can be explained that the literature found is more from quantitative research using the survey questionnaire method $(\mathrm{n}=7)$, whereas there are only four articles with the literature review method.

\section{DISCUSSION}

Objective of this study was to determine relation between parenting style (style of parenting) with the incidence obesitas or the impact on the child's weight. Parenting is a complex collection of habits from parents to children in various aspects, including physical, verbal, emotional display of affection and negativity, monitoring, discipline, and so forth. There are three types of relevant theories in the parenting category: theories of what aspects of parenting are important for child development, theories that influence parenting, and theories of changes in ethics and habits in parenting [6]. Parenting is a comprehensive term that refers to the overall attitudes, values, beliefs, and behaviors that parents show in their interactions with their children or children [7]. Over the past 60 years, the assessment of parenting has mainly focused on three categories: the centrality of the warmth and care of parents, the provision of structure, and the support of autonomy. These categories are conceptualized into six dimensions when their relationship to child development is examined, including warmth, rejection, structure, disorder, coercion and support for autonomy. To capture the complexity of childcare styles and understand their effects on child development, Diana Baumrind, defines several common types of parenting styles (Authoritative, Permissive, Authoritarian, and Neglectful) based on two dimensions, namely the demands and responses of parents, and several studies facilitate classification this is to overcome the relationship between parenting style and childhood obesity [8].

Parenting style is really needed for children in school and pre-school, because children are still considered to lack understanding of the right food choices for their bodies [9]. Authoritarian (authoritarian) refers to parenting that has 
high regulatory limitations but low in open communication. Authoritative parenting is an upbringing that is limited in regulation but also high in communication. Authoritarian parenting is parenting weak in regulations and also communication [9].

Parents directly affect a child's access to healthy or unhealthy food and allow or hinder physical activity and sedentary behavior at home [10]. Parents are a key player in the prevention and treatment of weight-related problems [11]. There is a relationship between parenting and obesity in children. Children who are in foster care with parenting style authoritarian will tend to experience obesity is 1.1 to 1.4 times that of the children in foster care with the style of parenting authoritative [12].

Several studies have shown that authoritative parenting is the least risky parenting model for a child's weight. [13-16]. Parenting pattern also associated with kea passage and the family of Chemish kinan also me am influenced style in child care [17].

On the other hand, excessive attention and involvement from parents can result in a higher risk of obesity and obesity among their children due to increased mental stress [18]. In addition, the relationship between a permissive parenting style and obesity puts children at a higher risk for being overweight or obese with [12] studies that show a positive relationship between permissive parenting style and child BMI [14].

When children are introduced to solid foods, they tend to like foods that are sweet and salty, calorie-dense, and reject new foods [19]. If parents do not continue to expose children to new foods and try to add variety to the child's diet, then it may be difficult for children to learn new foods such as vegetables [19]. Suppressing emotional mechanisms, excessive food consumption / energy intake and overweight and obesity have been set out in the research literature. Children from urban schools have a greater chance of being overweight when they report care that is very responsive and low [12].

\section{CONCLUSION}

Most of the studies reviewed agree that authoritative parenting is the best parenting to avoid children from obesity. Although there are many other variables that might affect the incidence of obesity in children.

\section{ACKNOWLEDGMENT}

In this study there are no funding donors for writing. So no one has influenced the writer's evaluation of certain articles.

\section{REFERENCES}

[1] WHO. Obesity. (2019). Available at: https:/www.who.int/topics/obesity/en/.
[2] Ayu, R. \& Sartika, D. FAKTOR RISIKO OBESITAS PADA ANAK 5-15 TAHUN DI INDONESIA. 15, 37-43 (2011).

[3] Kesehatan, K. \& Kesehatan, B. P. dan P. Hasil Utama Riskesdas 2018. (2018).

[4] Bjelanovic, J., Velicki, R., Popovic, M., Bjelica, A. \& Jevtic, M. Prevalence and some risk factors of childhood obesity. Prog. Nutr. 19, 138-145 (2017).

[5] Bahreynian, M. et al. Association between obesity and parental weight status in children and adolescents. JCRPE J. Clin. Res. Pediatr. Endocrinol. 9, 111-117 (2017).

[6] Feinberg, M. E. \& Pettit, G. S. Parenting, Adulthood. (2003).

[7] Baumrind, D. Baumrind1991.Pdf. (1991).

[8] Rhee, K. E., Pan, T. Y., Norman, G. J., Crow, S. \& Boutelle, K. Relationship between maternal parenting and eating self-efficacy in overweight children when stressed. 283-288 (2013). doi:10.1007/s40519-013-0043-x

[9] Gerards, S. M. P. L. \& Kremers, S. P. J. The Role of Food Parenting Skills and the Home Food Environment in Children' s Weight Gain and Obesity. 30-36 (2015). doi:10.1007/s13679-015-0139-x

[10] Patel, C., Karasouli, E., Shuttlewood, E. \& Meyer, C. Food parenting practices among parents with overweight and obesity: A systematic review. Nutrients 10, 1-23 (2018).

[11] Shloim, N., Edelson, L. R., Martin, N. \& Hetherington, M. M. Parenting styles, feeding styles, feeding practices, and weight status in 4-12 year-old children: A systematic review of the literature. Front. Psychol. 6, (2015).

[12] Tan, Z., Min, J., Xue, H., Wang, W. \& Wang, Y. Parenting practices and overweight status of junior high school students in China: A nationally representative study of 19,487 students from 112 schools. Prev. Med. (Baltim). 107, 1-7 (2018).

[13] Berge, J. M., Wall, M., Loth, K. \& Neumark-Sztainer, D. Parenting Style as a Predictor of Adolescent Weight and Weight-Related Behaviors. J. Adolesc. Heal. 46, 331-338 (2010).

[14] Vollmer, R. L. \& Mobley, A. R. Parenting styles, feeding styles, and their influence on child obesogenic behaviors and body weight. A review. Appetite 71, 232-241 (2013).

[15] Xu, H., Wen, L. M., Rissel, C., Flood, V. M. \& Baur, L. A. Parenting style and dietary behaviour of young children. Findings from the Healthy Beginnings Trial. Appetite 71, 171-177 (2013).

[16] Fuemmeler, B. F. et al. Parenting styles and body mass index trajectories from adolescence to adulthood. Heal. Psychol. 31, 441-449 (2012).

[17] Kakinami, L., Barnett, T. A., Séguin, L. \& Paradis, G. Parenting style and obesity risk in children. Prev. Med. 
(Baltim). 75, 18-22 (2015).

[18] Ek, A. et al. A Parent Treatment Program for Preschoolers With Obesity: A Randomized Controlled Trial. Pediatrics 144, e20183457 (2019).

[19] Anzman, S. L., Rollins, B. Y. \& Birch, L. L. Parental influence on children's early eating environments and obesity risk: Implications for prevention. Int. J. Obes. 34, 1116-1124 (2010). 